\title{
Prevalence of Aflatoxigenic Aspergillus Spp and Groundnut Resistance in Zimbabwe
}

\author{
Mandlenkosi Dube and Mcebisi Maphosa* \\ Lupane State University, Department of Crop and Soil Sciences, Box AC 255, Bulawayo, Zimbabwe \\ *mmaphosa@lsu.ac.zw
}

\begin{abstract}
Aspergillus species are major causes of pre- and post-harvest spoilage of groundnut. During 2013, the presence of aflatoxigenic Aspergillus species from groundnut sold from markets in Hwange, Gwanda, Umzingwane, Insiza, Beitbridge and Matobo markets in Zimbabwe were assessed. These represent areas of high groundnut production which experience recurrent drought, a major contributory factor in Aspergillus occurrence. The samples were separately analyzed for the presence of aflatoxigenic species Aspergillus flavus and A. parasiticus. The isolation of these species was carried out using direct plating methods and their identification based on macroscopic and microscopic criteria. A total of seven Aspergillus species of and other microbes were isolated from the collected namely A. flavus, A. niger, A. oryzae, A. parasiticus, A. terreus, A. tamari, A. nidullani and Rhizopus spp. However, there were variations in the degree of occurrence of each of the two species in each of these samples. The important isolates of A. flavus and A. parasiticus that cause aflatoxins were inoculated in vitro on eleven groundnut genotypes obtained from the Crop Breeding Institute, Zimbabwe and Seed-Co Private Limited for their response to seed colonisation and infection. No variety was immune to the two Aspergillus spp, however, variety CG7 and Mwenje together with IIanda and Nyanda had a relatively longer incubation period for A. flavus and A. parasiticus respectively. During the seed resistance status test only three genotypes (Falcon, CG 7 and Nyanda) were found to be moderately resistant to infection by A. flavus and the remaining eight genotypes (Makulu Red, Tern, Teal, Mwenje, SC Orion, Flamingo and SC GV 00004) were susceptible in the laboratory tests. All the varieties succumbed to A. parasiticus during the seed resistance test. Overall, these results show the presence of aflatoxigenic Aspergillus spp in groundnuts in some Zimbabwean markets. Moreover, there is limited genetic resistance in groundnut to the A. flavus and A. parasiticus in the available genotypes implying great consumer risk.
\end{abstract}

\section{Introduction}

Groundnut (Arachis hypogea L.) is one of the most important legume crops of tropical and semi arid tropical countries, which provides edible oil and vegetable protein (FAO, 2010; ICRISAT, 1993). The productivity of groundnut however, varies from $3500 \mathrm{~kg} / \mathrm{ha}$ in the United States to less than $800 \mathrm{~kg}$ in Africa. Smallholder farmer groundnut yields are low, but encouraging yields have been achieved with improved production and postharvest practices on research stations (FAO, 2007). Traditionally, the bulk of Zimbabwe's groundnut is produced by smallholder farmers and accordingly, any constraints that threaten groundnut are likely to impact negatively on the livelihoods of many rural households.

The agro climatic environment for groundnut production is very diverse and $70 \%$ of the crop area is under semi-arid tropics characterized by low and erratic rainfall. Improper pre- and post harvesting management techniques through inadequate drying and storage facilities are among the major constraints in producing quality groundnuts (Okello et al., 2010). Groundnut is a semi perishable commodity; under unsuitable storage conditions may become inedible in less than a month due to molds, insects or development of undesirable flavor characteristics (Craufurd et al., 2006). This has negatively affected the realization of high economic benefits from groundnut production in the region as well as increased veterinary and medical costs incurred after Aspergillus infections (Kaaya et al., 2006).

The growth of Aspergillus spp and consequent aflatoxin production is dependent upon a number of factors such as temperature, humidity and kernel moisture content (Polixeni and Panagiota, 2008; Mutegi, 2010). Groundnut crops growing in semi-arid climates where there is the likelihood of drought are particularly at risk to post-harvest contamination. Furthermore, high seed moisture content during storage also increases the risk of contamination (Bhatnagar et al., 2006). The risk of contamination in groundnut increases along the marketing chain due to poor handling practices (Kaaya et al., 2006). Smallholder and marginal farmers, especially in developing countries such as Zimbabwe cannot afford the agronomic costs that can reduce the incidence of Aspergillus spp contamination. Farmers' current production and post-harvest practices compounded by labour shortages and use of unimproved cultivars are likely to increase the chances of aflatoxin contamination. Chronic intake of aflatoxin in animals can lead to poor food intake and weight loss affecting market prices and quality of the meat products. In a study by Mutegi et al. (2012), 37\% of groundnuts and their 
products including peanut butter and peanut flour sampled from Nairobi, Nyanza and Western Kenya did not meet the $10 \mu \mathrm{g} / \mathrm{kg}$ total aflatoxin limit set by the Kenya Bureau of Standards (KEBS, 2007). In Zimbabwe, the standard aflatoxin B level for grain for human consumption has been set at $5 \mathrm{ppm}$ (Nziramasanga, 2014). However, the majority of smallholder farmers, traders and consumers in the region are not currently aware of the Aspergillus pathogen invasion and aflatoxin contamination of food and feed. The need to study the prevalence of Aspergillus spp causing organisms and genotype resistance can provide necessary information for use in formulating and designing strategies to prevent or reduce future prevalence of the pathogen.

\section{Groundnut sample collection}

\section{Materials and Methods}

Harvested groundnut seed samples were collected from major drought-prone groundnut producing areas across Matabeleland province in Zimbabwe (Figure 1). Overall 33 composite samples of groundnuts were randomly collected from different markets of Hwange, Gwanda, Umzingwane, Insiza, Beitbridge, Matobo and information on varieties, post harvest practices, field history, and problems encountered in the season were collected. All the samples were collected in the dry season between July and October 2013. Collected samples consisted of raw shelled groundnut only that were kept in dry ice during transportation to the laboratory.

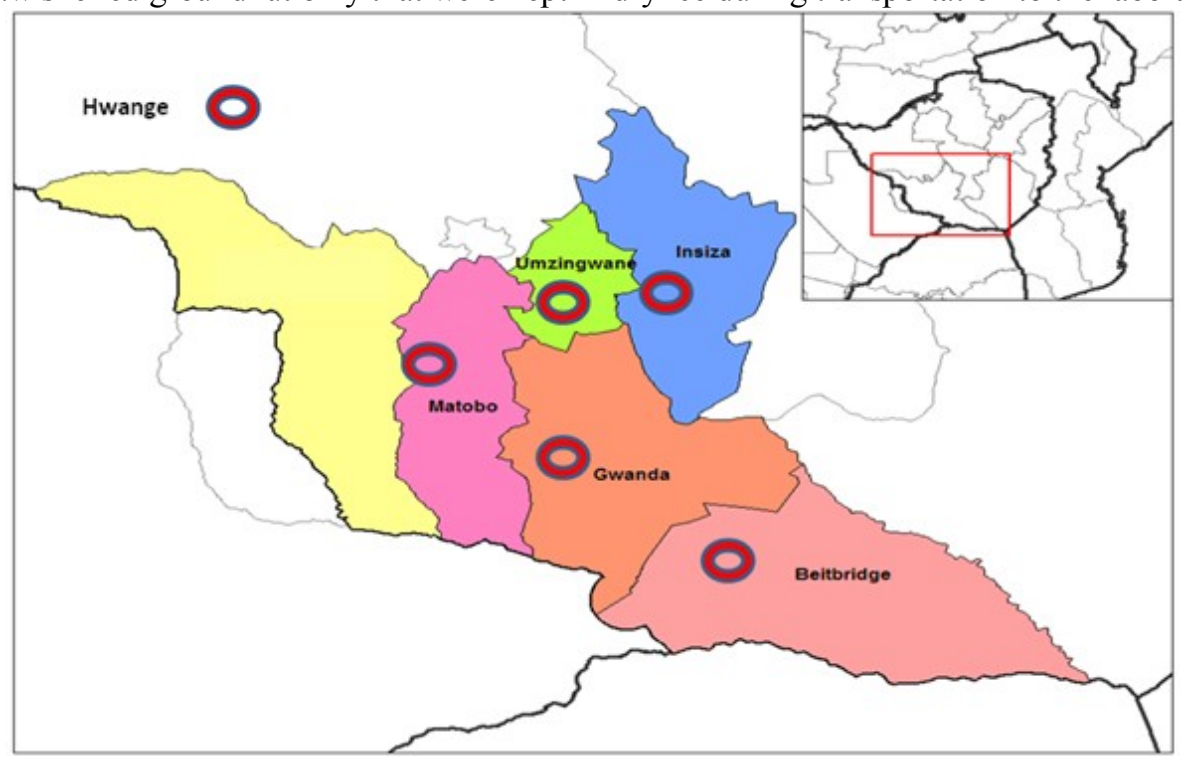

Figure1. Selected drought prone districts of Matabeleland where shelled market groundut samples were collected.

\section{Pathogen identification}

Fungi were isolated using the direct plating method in petri dishes. Six hydrated seed samples from each location were sterilized using $70 \%$ ethanol for 2 minutes and placed in the V8 medium and stored at room temperature under $100 \%$ relative humidity for 21 days. Fungal pathogens were identified under a microscope $\times$ 100 using colonial morphology, fruiting bodies, mycelia and microscopic appearances and characterization (Clement et al., 2013).

\section{Groundnut seed resistance to seed invasion and colonization}

An investigation into available eleven groundnut genotypes from the Crop Breeding Institute (CBI) in Zimbabwe and Seed-Co Zimbabwe was done to evaluate them for resistance to Aspergillus invasion and colonization (Table 1). The in vitro inoculation method was used for screening groundnut resistance using invasion and colonization indices for A. flavus and A. parasiticus the most devastating of the aflatoxigenic fungi. Six hydrated seed samples per cultivar were surface sterilized using $70 \%$ ethanol solution for 2 minutes prior to inoculation and colonization with a standardized conidial suspension of the two aflatoxigenic Aspergillus species: A. flavus and A. parasiticus. The seeds were kept at room temperature at $100 \%$ relative humidity for 14 days. Qualitative observations were made from each Petri dish for genotype resistance to seed colonization and invasion by the aflatoxigenic fungi. All data we analysised using descriptive stastics. 
Table 1. List of genotypes evaluated for Aspergillus spp seed invasion and colonization

\begin{tabular}{lll}
\hline Genotype & Source & Type \\
\hline Falcon & CBI, Zimbabwe & Spanish \\
CG 7 & Seed-Co, Zimbabwe & Virginia \\
Mwenje & Seed-Co, Zimbabwe & Valencia \\
Ilanda & CBI, Zimbabwe & Valencia \\
SC Orion & Seed-Co, Zimbabwe & Virginia \\
Teal & Seed-Co, Zimbabwe & - \\
Nyanda & CBI, Zimbabwe & Spanish \\
Flamingo & CBI, Zimbabwe & Spanish \\
SC GV 00004 & Seed-Co, Zimbabwe & - \\
Makulu Red & CBI, Zimbabwe & Virginia \\
Tern & Seed-Co, Zimbabwe & - \\
\hline
\end{tabular}

\section{Results}

Prevalence of aflatoxigenic Aspergillus species

From the collected samples, a total of eight different Aspergillus species were positively identified and these included A. flavus and A. parasiticus as potent aflatoxin producers (Figure 1). However, other pathogens identified included A. terrens, A. Oryzae, A. tamari, A. niger, A. nidulani and Rhizopus spp across the various markets (Table 2).

Table 2. Overall total observation of the fungal diversity across the sampled markets

\begin{tabular}{lllllllll}
\hline $\begin{array}{l}\text { Market } \\
\text { Area }\end{array}$ & $\begin{array}{l}\text { Rhizopus } \\
\text { spp }\end{array}$ & $\begin{array}{l}\text { A. } \\
\text { Terens }\end{array}$ & $\begin{array}{l}\text { A. } \\
\text { flavus }\end{array}$ & $\begin{array}{l}\text { A. } \\
\text { oryzae }\end{array}$ & $\begin{array}{l}\text { A. } \\
\text { tamarii }\end{array}$ & $\begin{array}{l}\text { A. } \\
\text { niger }\end{array}$ & $\begin{array}{l}\text { A. } \\
\text { nidulans }\end{array}$ & $\begin{array}{l}\text { A. } \\
\text { parasiticus }\end{array}$ \\
\hline Hwange & 4 & 1 & 1 & 1 & 2 & 1 & 1 & 0 \\
Gwanda & 8 & 0 & 0 & 3 & 2 & 4 & 6 & 1 \\
Umzingwane & 1 & 1 & 0 & 1 & 1 & 2 & 1 & 0 \\
Insiza & 1 & 0 & 0 & 0 & 0 & 0 & 1 & 0 \\
Beitbridge & 1 & 0 & 1 & 0 & 0 & 1 & 1 & 0 \\
Matobo & 8 & 2 & 0 & 0 & 5 & 2 & 5 & 1 \\
Total & 23 & 4 & 2 & 5 & 10 & 10 & 15 & 2 \\
\hline
\end{tabular}

The number of the fingal species identified in the various markets showed greater preponderance of Rhizopus spp. Hwange markets had the greatest microbial species diversity whereas Insiza had the least (Table 2).

\section{Groundnut seed resistance to seed invasion and colonisation}

Eleven groundnut genotypes were tested for seed resistance, invasion and colonization by A. flavus and A. parasiticus isolates from the local markets. Based on infection progression for the test genotypes for the two aflatoxigenic Aspergillus species; A. flavus and A.parasiticus, the former was more aggressive developing on more genotypes at six and eight days (Figure 2).
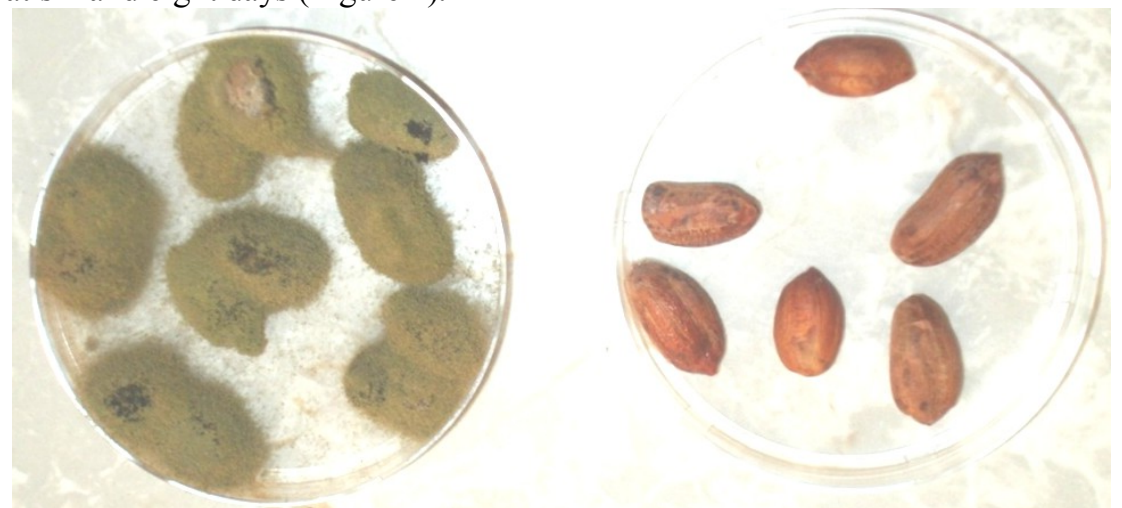

Figure 2. Heavily infested groundnuts (left) with Aspergillus flavus symptoms next to un infested ones (right) 6 days after incubation

No genotype was immune to Aspergillus spp infection and colonisation. Of the eleven ground nut genotypes tested, the varieties CG 7 and Mwenje took eight days to develop A. flavus. Similarly, IIanda and Nyanda took 8 days to develop A. parasiticus. Makulu red was the most susceptible variety with the least incubation periods across the two species (Table 3). 
Table 3. Seed infection rate for the two aflatoxigenic Aspergillus species

\begin{tabular}{|c|c|c|c|c|c|c|c|c|c|c|c|c|}
\hline \multirow{3}{*}{ Genotype } & \multicolumn{6}{|c|}{ Aspergillus flavus } & \multicolumn{6}{|c|}{ Aspergillus parasiticus } \\
\hline & \multirow[b]{2}{*}{4} & \multicolumn{4}{|c|}{ Days to development } & \multirow[b]{2}{*}{14} & \multicolumn{6}{|c|}{ Days to development } \\
\hline & & 6 & 8 & 10 & 12 & & 4 & 6 & 8 & 10 & 12 & 14 \\
\hline Falcon & - & Dev & $\mathrm{Wt}$ & G & G & G & - & - & - & - & Br.G & Br.G \\
\hline CG 7 & - & - & Dev & G & B.G & B.G & - & Dev & Br.G & Br.G & Br.G & Br.G \\
\hline Mwenje & - & - & Dev & G & G & B.G & - & Dev & $\mathrm{G}$ & G & G & G \\
\hline Ilanda & - & Dev & $\mathrm{G}$ & $\mathrm{G}$ & $\mathrm{G}$ & B.G & - & - & Dev & Br.G & Br.G & Br.G \\
\hline SC Orion & - & Dev & G & $\mathrm{G}$ & B.G & B.G & - & Dev & Br.G & Br.G & Br.G & Br.G \\
\hline Teal & Dev & $\mathrm{Wt}$ & $\mathrm{Wt}$ & G & $\mathrm{G}$ & G & Dev & B.G & Br.G & Br.G & Br.G & Br.G \\
\hline Nyanda & - & Dev & $\mathrm{G}$ & G & G & B.G & - & - & Dev & Br.G & Br.G & Br.G \\
\hline Flamingo & - & Dev & $\mathrm{G}$ & $\mathrm{G}$ & G & $\mathrm{G}$ & Dev & G & $\mathrm{G}$ & Br.G & Br.G & Br.G \\
\hline SC GV 00004 & - & Dev & G & G & B.G & B.G & - & Dev & G & Br.G & Br.G & Br.G \\
\hline Makulu Red & Dev & $\mathrm{G}$ & $\mathrm{G}$ & G & B.G & B.G & Dev & $\mathrm{G}$ & G & $\mathrm{G}$ & $\mathrm{G}$ & G \\
\hline Tern & Dev & G & G & $\mathrm{G}$ & B.G & B.G & - & Dev & $\mathrm{G}$ & $\mathrm{G}$ & $\mathrm{G}$ & $\mathrm{G}$ \\
\hline
\end{tabular}

-No mycelia, Dev-Development of mycelia, Wt-White mycelia, B.G.-Black Green mycelia, Br.G-Bright Green mycelia

Despite the fact that all varieties succumbed to infestation, the percentage colonization was variable. For A. flavus, genotypes Falcon, CG 7 and Nyanda were resistant using an arbitrary 50\% cut off point. Aspergillus parasiticus had broad spectrum virulence overcoming all the test genotypes.

Table 4. The resistance status of the eleven genotypes based on percentage infection of A. flavus

\begin{tabular}{|c|c|c|c|c|}
\hline \multirow[b]{2}{*}{ Genotype } & \multicolumn{2}{|c|}{ Aspergillus flavus } & \multicolumn{2}{|c|}{ Aspergillus parasiticus } \\
\hline & Percentage infestation & Response & Percentage infestation & Response \\
\hline Falcon & 42 & $\mathrm{R}$ & 75 & $\mathrm{~S}$ \\
\hline CG 7 & 17 & $\mathrm{R}$ & 100 & $\mathrm{~S}$ \\
\hline Mwenje & 100 & $\mathrm{~S}$ & 75 & $\mathrm{~S}$ \\
\hline Ilanda & 92 & $\mathrm{~S}$ & 100 & $\mathrm{~S}$ \\
\hline SC Orion & 100 & $\mathrm{~S}$ & 100 & $\mathrm{~S}$ \\
\hline Teal & 100 & $\mathrm{~S}$ & 100 & $\mathrm{~S}$ \\
\hline Nyanda & 33 & $\mathrm{R}$ & 75 & $\mathrm{~S}$ \\
\hline Flamingo & 100 & $\mathrm{~S}$ & 100 & $\mathrm{~S}$ \\
\hline SC GV 00004 & 100 & $\mathrm{~S}$ & 83 & $\mathrm{~S}$ \\
\hline Makulu Red & 100 & $\mathrm{~S}$ & 83 & $\mathrm{~S}$ \\
\hline Tern & 100 & $\mathrm{~S}$ & 92 & $\mathrm{~S}$ \\
\hline Mean & $80.36 \pm 10$ & & $89.36 \pm 5$ & \\
\hline
\end{tabular}

S-Susceptible, R-Resistant

\section{Discussion}

Farmers' practices of production and handling of groundnut at pre- and post-harvest stages may have provided favorable conditions for outbreaks of fungi and their mycotoxins. The study showed that the most predominant genus Aspergillus accounted for seven different species in the culture media and this corraborates Ndungu et al. (2013) who noted that Aspergillus spp are the most ubiquitous groundnut fungi.

Mixon and Rogers (1986) suggested that use of groundnut cultivars with resistance to seed invasion and colonization by toxigenic Aspergillus species would be an effective means of preventing aflatoxin contamination. A significant positive correlation between in vitro resistance and field resistance was observed (Mixon, 1986; ICRISAT, 1989). The present study clearly demonstrated genotypic differences in the level of seed colonisation by A. flavus and A. parasiticus. The lack of effective resistance in the majority of test varieties could be indicative of a limited scope for selection for resistance breeding. Falcon, CG 7 and Nyanda showed some degree of in vitro resistance to seed colonisation by A. flavus, while susceptible to A. parasiticus. This could imply the seed resistance to two Aspergillus species is independent of each other. Furthermore, this could explain the fact that all genotypes were susceptible to Aspergillus parasiticus compared to Aspergillus flavus despite its slow colonisation rate. The resistance response of some genotypes, Falcon, CG 7 and Nyanda to in vitro seed colonisation by A. flavus in different screening experiments could be explained by the presence of certain seed coat features such as permeability, wax and tannin content (Mixon, 1986; Liang et al., 2003).

\section{Conclusions And Recommendations}

The presence of aflatoxin-producing species of Aspergillus and other non aflatoxin producing species in foods and foodstuffs should be of great concern to the producers, sellers and consumers. There is very limited scope to breed for seed resistance from the available groundut varieties suggesting the need to prospect for new sources resistance. Future studies aimed at quantifying the aflatoxin levels in the collected samples using techniques such as High Pressure Liquid Chromatography (HPLC) are recommended. 


\section{Acknowledgements}

The authors wish to acknowledge Mr T. Kachote for the technical assistance and the department of Crop and Soil Sciences

\section{References}

[1]. Bhatnagar D, Cary JW, Ehrlich K, Yu J, Cleveland TE (2006). Understanding the genetics of regulation of aflatoxin production and Aspergillus flavus development. Mycopathologia 2006; 162: 155-66.

[2]. Clement Abrida, J, A. Lennox, Bassey F, Asikong atim Asitom Ikpoh S. Ikpoh, Effiom E. Henshaw, Mathew E. Eja. Isolation of aflatoxin producing spp of Aspergillus from food stuffs sold in calabar markets, Cross River state, Nigeria. J. microbiol. Biotech, Res, 2013, 3 (1): 8-13

[3]. Craufurd, P.Q., Prasad, P.V.V., Waliyar, F. and Taheri, A. (2006). Drought, Pod Yield, Pre-harvest Aspergillus Infection and Aflatoxin Contamination on Peanut in Niger. Field Crop Research, 98:20-29.

[4]. FAOSTAT (2010) Groundnut world production.http://www.faostat.fao.org. Food and Agricultural Organization, Rome, Italy.

[5]. FAO (2007). Agricultural Crop Production Statistics, available at www.fao.org/faostat. Food and Agricultural Organization, Rome, Italy.

[6]. ICRISAT (International Crops Research Institute for the Semi Arid Tropics) 1989. Aflatoxin contamination of groundnut: Proceedings of the International workshop, 6-9 October 1987, Patancheru, India.

[7]. ICRISAT (International Crops Research Institute for the Semi Arid Tropics) 1993. Nutritive value and uses of pigeon pea and groundnut. Skills development series No 14. Patancheru, India.

[8]. Kaaya AN, Harris C, Eigel W, 2006. Peanut aflatoxin levels on farms and in markets of Uganda.

[9]. Peanut Science 33: $68-75$.

[10]. KEBS, 2007. Kenya Standard KS 694-1: 2007.Shelled groundnut (Arachis hypogaea Linn.) Specification. Part 1: Raw Groundnut forTable Use. Kenya Bureau of Standards

[11]. Documentation Centre, Nairobi, Kenya.

[12]. Liang, X.Q., Zhou, G.Y and Pan, R.Z. 2003. Study on the relationship of wax and cutin layers in peanut seeds and resistance to invasion and aflatoxin production by Aspergillus flavus. Journal of Tropical and Sub tropical Botany 11: 11-14.

[13]. Mixon, A.C., and Rogers, K.M. 1973. Peanut accessions resistant to seed infection by Aspergillus flavi. Agronomy Journal 65:560562 .

[14]. Mixon, A.C, 1986. Reducing Aspergillus species infection of peanut seed using resistant genotypes. Journal Envorn Quan

[15]. Mutegi C. K 2010. The extent of aflatoxin and Aspergillus Section flavi, Penicillium spp. and Rhizopus spp. Contamination of peanuts from households in western Kenya and causative factors of contamination. PhD Thesis, University of Kwazulu-Natal, Pietermaritzburg, South Africa

[16]. Ndung'u, J. W., Makokha, A.O., Onyango, C.A., Mutegi, C.K, Wagacha, J.M., Christie, M.E and Wanjoya, A.K. 2013. Prevalence and potential for aflatoxin contamination in groundnuts and peanut butter from farmers and traders in Nairobi and Nyanza provinces of Kenya. Journal of Applied Biosciences 65:4922-4934.

[17]. Nziramasanga, N. 2014. Aflatoxins in Zimbabwe, Legislative Frameworks Against Level of

[18]. Awareness: A Perspective from a Laboratory. Paper presented at Huang Shan Hall, Peacock Hotel, Lilongwe, Malawi

[19]. Okello, D.K., Kaaya, A.N., Were, M and Oloka, H.K. 2010. Management of aflatoxins in groundnuts: A manual for farmers, processor, traders and consumers in Uganda. National Agricultural Research Organisation, Entebbe, Uganda.

[20]. Polixeni V. and Panagiota M, 2008. Aflatoxin B1 and ochratoxin A in breakfast cereals from

[21]. Athens market: Occurrence and risk assessment. Lab of food chemistry, Department of chemistry, University of Athens, Panepistimiopolis, 15784 Athens, Greece. 